Original Research

\title{
Wind-Stress Variations from Deep to Shallow Water during Hurricanes for Air-Sea-Land Interaction Applications
}

Shih-Ang Hsu *

Louisiana State University, Baton Rouge, LA 70803, USA; E-Mail: sahsu@|su.edu

* Correspondence: Shih-Ang Hsu; E-Mail: sahsu@lsu.edu

Academic Editor: Zed Rengel

Special Issue: Air-Sea Interaction and Marine Meteorology

Adv Environ Eng Res

2022, volume 3, issue 1

doi:10.21926/aeer.2201006
Received: December 27, 2021

Accepted: February 03, 2022

Published: February 14, 2022

\begin{abstract}
In September 2020 Hurricane Sally impacted two National Data Buoy Center (www.ndbc.noaa.gov) buoys near its track: 42040 in the deep water and 42012 in the shallow. Using pertinent air-sea interaction formulas from the literature, analyses of these buoy data indicate that, under fully rough airflow and wind sea conditions, $U_{*}=a H_{s}{ }^{2} / T_{p}{ }^{3}+b$, here $U_{*}$ is the friction velocity, $H_{\mathrm{s}}$ is the significant wave height, and $T_{\mathrm{p}}$ is the peak wave period. It is found that $a=28$ and $b=0.12$ for the deep water environment, $a=30$ and $b=0.26$ for the shoaling wave environment, and $a=31$ and $b=0.14$ for the transitional water-depth environment, respectively. All units are in SI. Verifications and applications of these proposed formulas to estimate storm surge, wind speed, surface currents and seabed scours are presented. Because an extensive network for monitoring waves along the coastlines of the United States by the Coastal Data Information Program (CDIP) (CDIP About (ucsd.edu)), these proposed formulas are particularly useful. In addition, it is demonstrated that the parameter of wave steepness can be used to explain why there are large variations in the drag coefficient and wave-age formulations in the literature.
\end{abstract}

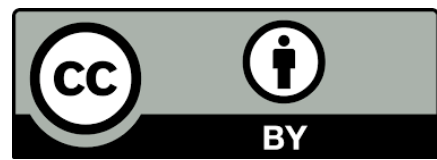

(C) 2022 by the author. This is an open access article distributed under the conditions of the Creative Commons by Attribution License, which permits unrestricted use, distribution, and reproduction in any medium or format, provided the original work is correctly cited. 


\section{Keywords}

Friction velocity; significant wave height; peak wave period; wave steepness; Hurricanes; airsea-land interactions

\section{Introduction}

The wind stress $\left[\tau=\rho U_{*}{ }^{2}=\rho C_{d} U_{10}{ }^{2}\right.$, in Pascal or $\mathrm{N} \mathrm{m}^{-2}$, here $\rho\left(\approx 1.2 \mathrm{~kg} \mathrm{~m}^{-3}\right)$ is the air density for the moist tropical air, $U_{*}$ is the friction velocity in $\mathrm{m} \mathrm{s}^{-1}, C_{d}$ is the drag coefficient and $U_{10}$ is the wind speed at $10 \mathrm{~m} \mathrm{in} \mathrm{m} \mathrm{s}^{-1}$ ] on the water surface affects nearly all air-sea-land interaction processes, see, e.g., [1, 2] for deep and [3, 4] for shallow water environments, respectively. For extensive reviews of the wind stress formulations over deep and shallow water, see, e.g. [5, 6]. However, as indicated in the literature, large variations in $C_{d}$ exist. In addition, information on the variation of wind stress from deep to shallow water under the influence of the same atmospheric forcing such as during a tropical cyclone are lacking. Therefore, the aim of this article is to bypass the usage of $C_{d}$ but to relate the $U_{*}$ (for the atmospheric forcing) and wave parameters (for the ocean response) directly.

In 2020, the National Data Buoy Center (www.ndbc.noaa.gov) maintained two buoys (42040 at water depth of 192 meters and 42012 at $23.5 \mathrm{~m}$ ) during the passage of Hurricane Sally (see Figure 1 for their locations with respect to the Sally's track). During a tropical cyclone (TC) worldwide, the Regional and Mesoscale Meteorology Branch (RAMMB) of NOAA/NESDIS (http://rammb.cira.colostate.edu/) issues real-time TC surface wind analysis. On the basis of these analyses, Figures 2 and 3 indicate that there were persistent onshore winds which impacted the meteorological and oceanographic (met-ocean) conditions at Buoy 42012 where the air pressure dropped from 1010 to $970 \mathrm{hPa}$ as depicted in Figure 4 as the wind speed (Figure 5) at 3.8m increased from 15 to $32 \mathrm{~m} \mathrm{~s}^{-1}$. During the same period, the wave direction was persistently onshore (Figure 6) and wave steepness (Figure 7) increased from 0.02 to over 0.05 for the wind seas [7] (for the definition, see next section). This event provides us an opportunity to diagnose the variations of wind stress from deeper sea at Buoy 42040 to the shallower water at 42012 using the met-ocean datasets as measured by these two NDBC buoys during Sally. After these evaluations, practical formulas to estimate the wind stress from deep to shallow waters will be provided for air-sea-land interaction investigations. Examples for these applications are also given. Since the wind stress formulation in the deep water has been provided elsewhere [8], this report may be considered as a supplement of that article. 


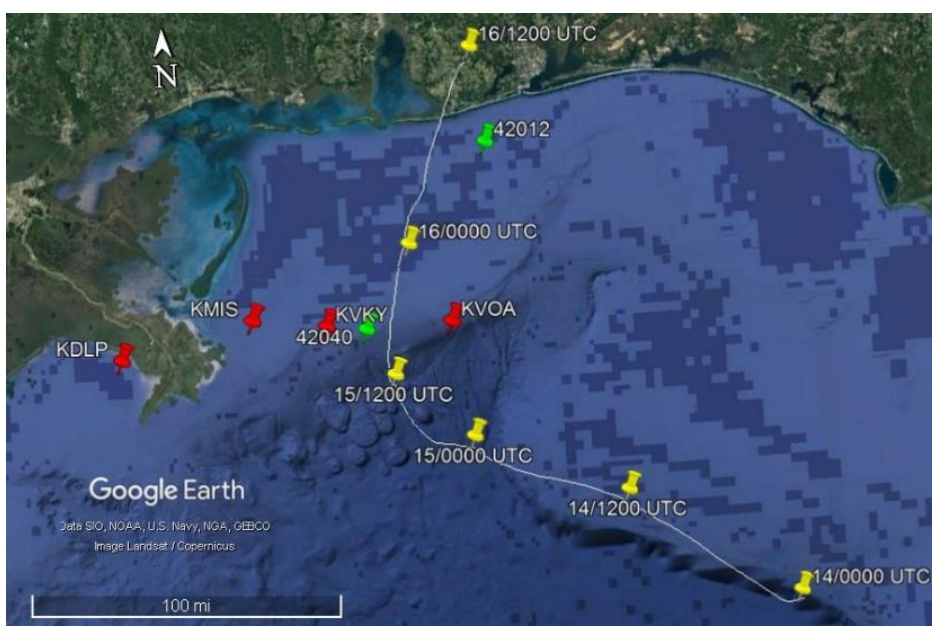

Figure 1 Portions of Sally's track (in yellow pins from 14 to16 September 2020) which affected our study area when it was over the north central Gulf of Mexico based on $\underline{2020}$ Atlantic Hurricane Season (noaa.gov) see www.nhc.noaa.gov/data/trc/. Red pins are for the routine Automated Surface Observing System (ASOS) stations and green ones for the NDBC buoys (see www.ndbc.noaa.gov).

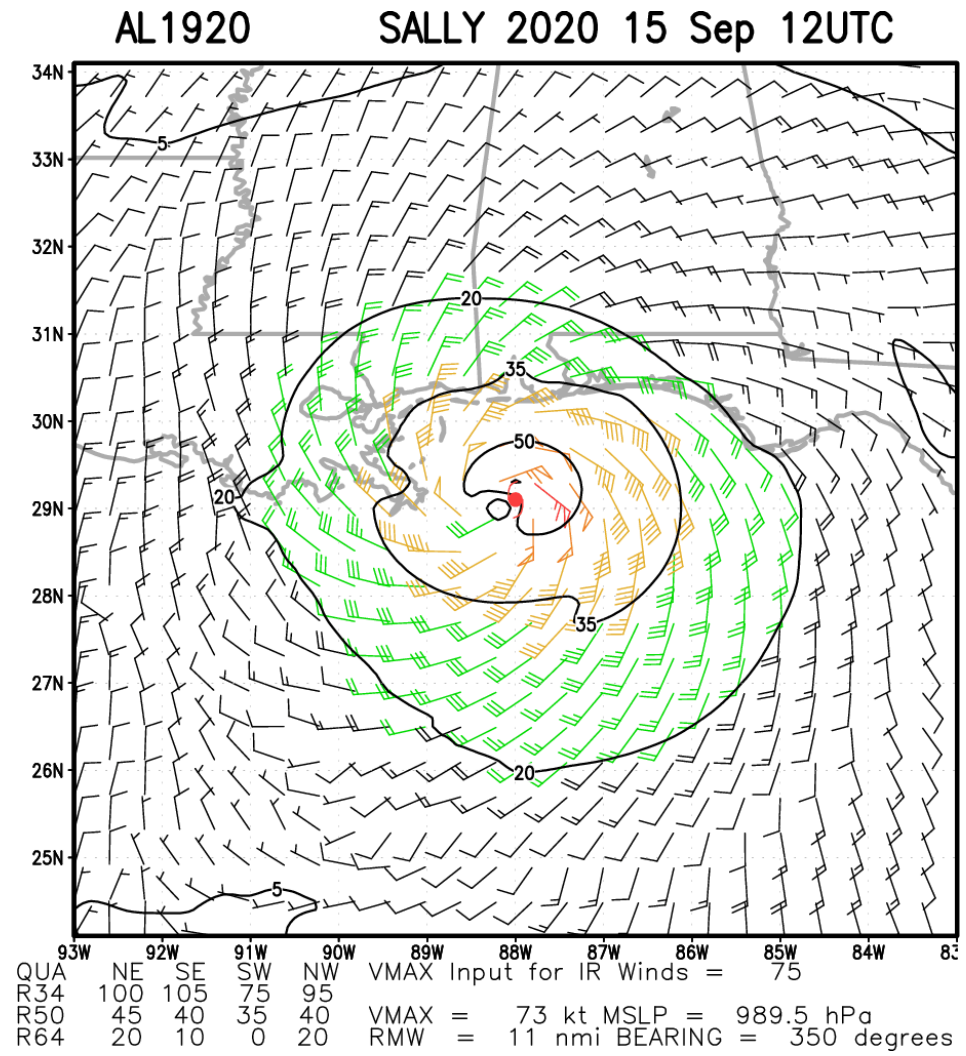

Figure 2 Variations of wind speed (in knots; 1 knot equals approximately $0.51 \mathrm{~m} \mathrm{~s}^{-1}$ ) and direction including the isotachs (equal wind speed lines) near Buoy 42040 at 12 UTC on 15 September 2020 during Sally based on RAMMB: TC Real-Time: AL192020 - Hurricane SALLY - Multiplatform Satellite Surface Wind Analysis (Experimental) (colostate.edu). For the explanation of multi-platform tropical cyclone surface wind analysis at $10 \mathrm{~m}$ over the ocean, see RAMMB: TC Real-Time: Descriptions of Products (colostate.edu). 


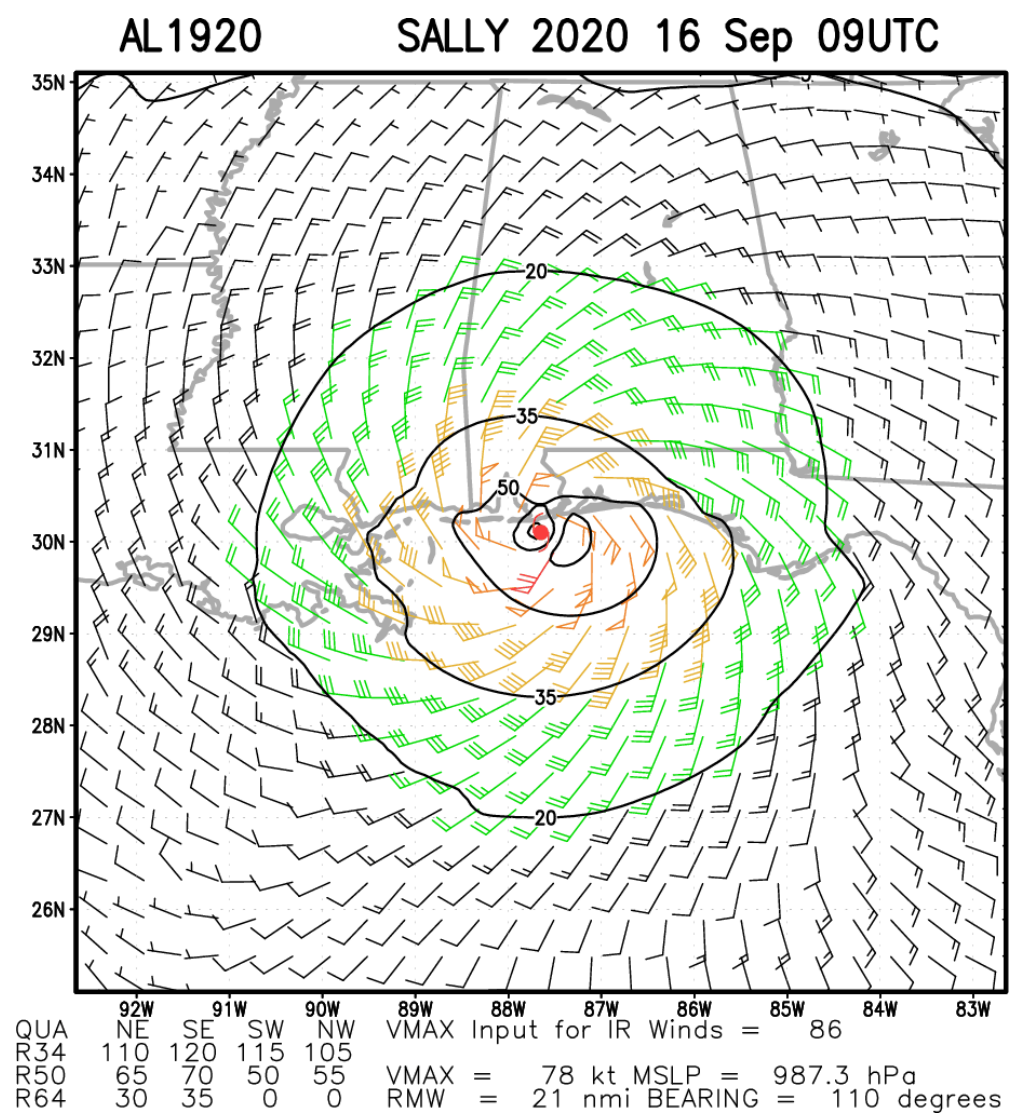

Figure 3 Same as Figure 2 but for wind speed and direction near Buoy 42012 at 09UTC on 16 September 2020 during Sally.

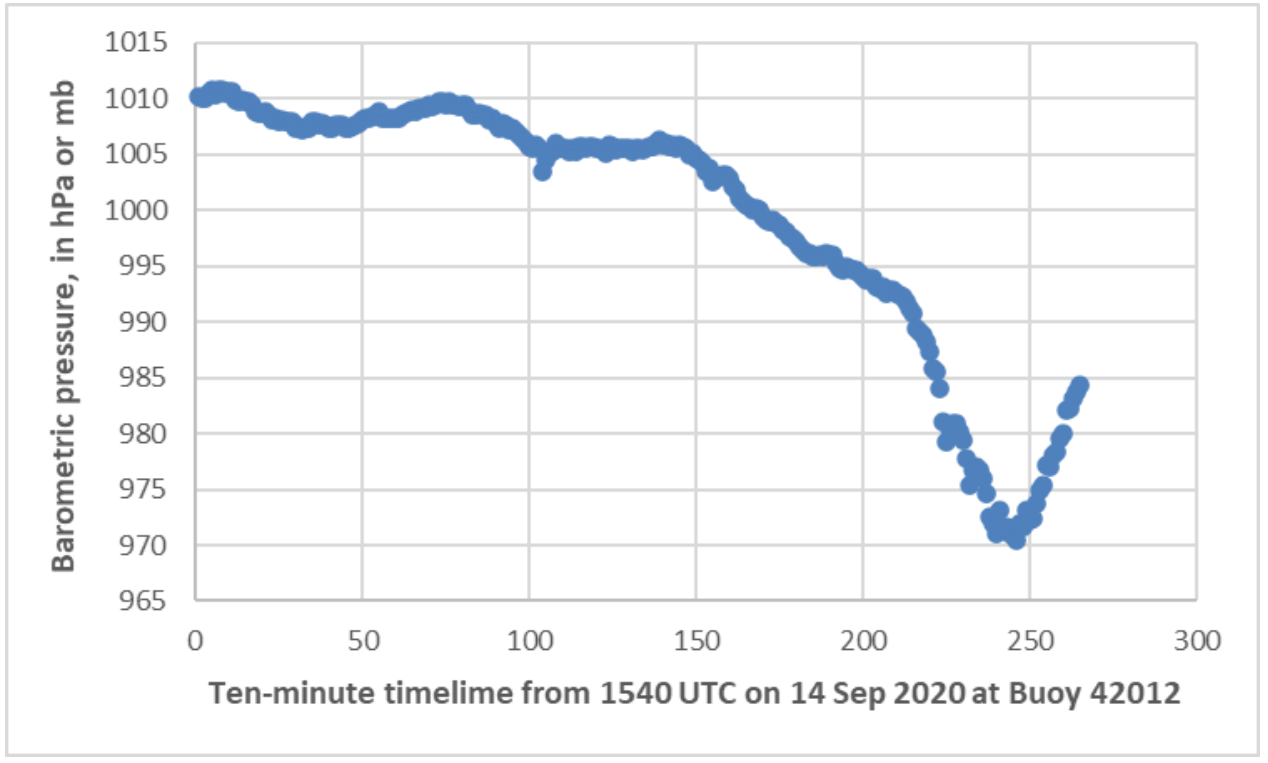

Figure 4 Measurements of atmospheric pressure at Buoy 42012 during Sally. 
Adv Environ Eng Res 2022; 3(1), doi:10.21926/aeer.2201006

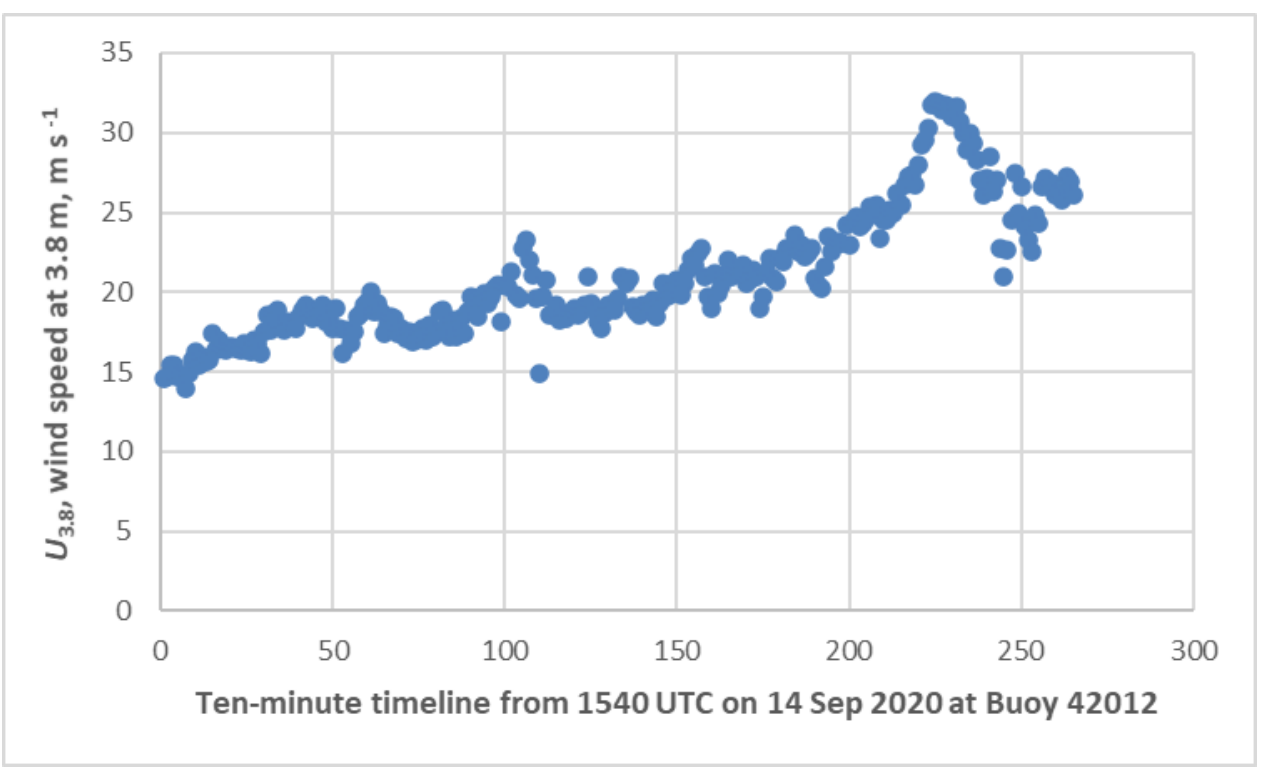

Figure 5 Measurements of the wind speed at $3.8 \mathrm{~m}$ at Buoy 42012 during Sally.

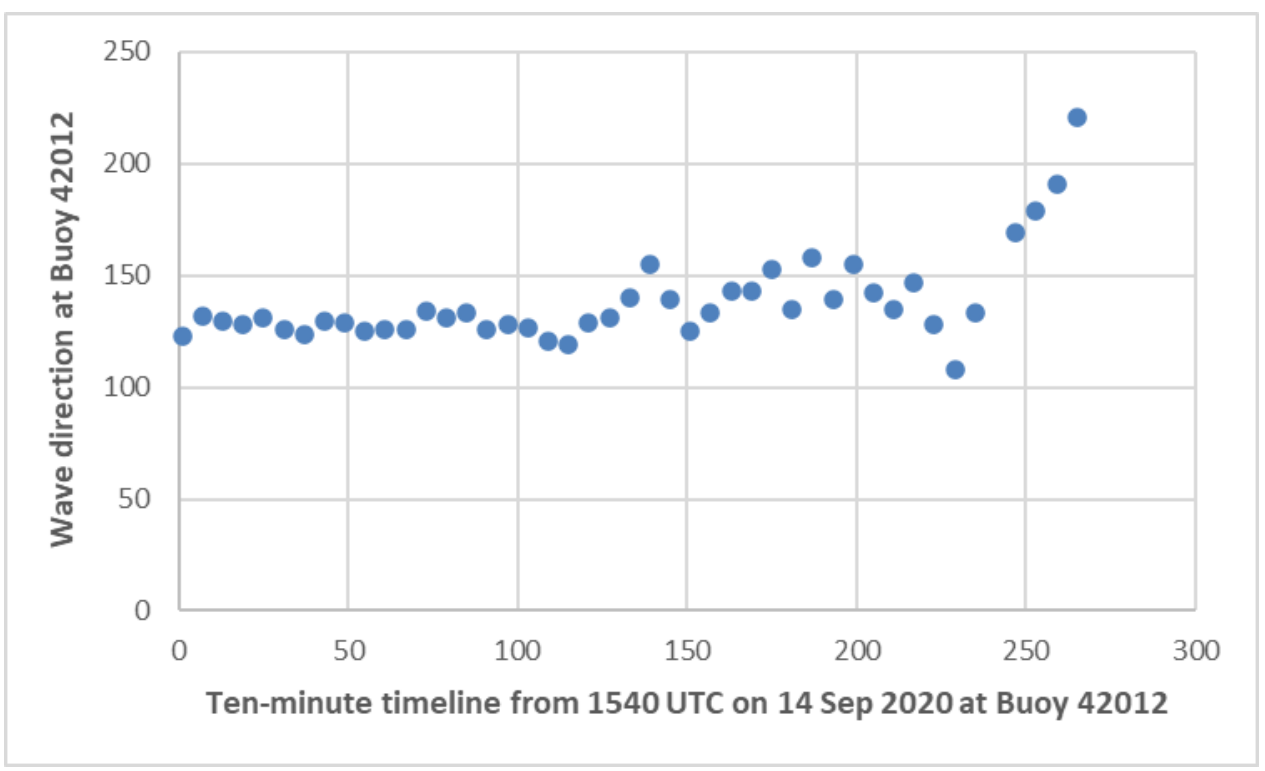

Figure 6 Measurements (available hourly) of the wave direction at Buoy 42012 during Sally. 


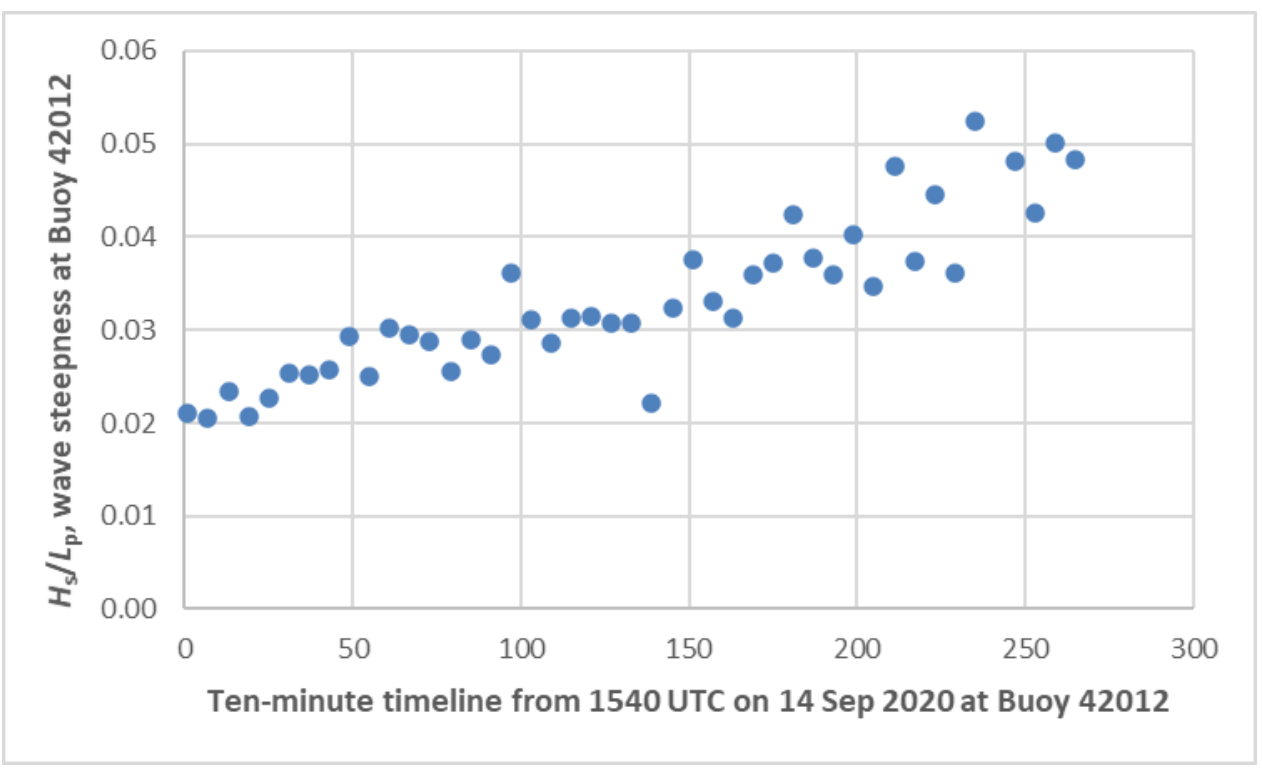

Figure 7 Measurements of wave steepness (available hourly) at Buoy 42012 during Sally (for the definition of wave steepness and criterion for the wind sea, see [7]).

\section{Methods}

At the air-sea interface when the mechanical turbulence dominates the vertical temperature stratification, the dry-adiabatic lapse rate at approximately $-1^{\circ} \mathrm{C}$ per $100 \mathrm{~m}$ prevails, so that the logarithmic wind profile exists such that [9-11]

$$
U Z=(U * / k) \ln \left(Z / Z_{o}\right)
$$

Here $U_{z}$ is the wind speed at height $Z, k(=0.4)$ is the von Karman constant, and $Z_{\mathrm{o}}$ is the aerodynamic roughness length.

To ensure that Equation (1) is valid in our study area during Sally, Table 1 is provided. Because the vertical temperature gradient is $(26.7-27.9) /(160-3.8)=-0.0077$ or $-0.77 / 100 \mathrm{~m}$, dry adiabatic lapse rate or neutral stability (D) prevailed, see, e.g., [11] (Table A.3).

Table 1 Thermodynamic conditions in the study area during Sally in September 2020.

\begin{tabular}{ccccc}
\hline Station & $Z, \mathrm{~m}$ & $T_{\text {air }}{ }^{\circ} \mathrm{C}$ & $T_{\text {dew }}{ }^{\circ} \mathrm{C}$ & $\mathrm{LCL}^{*}, \mathrm{~m}$ \\
\hline Buoy 42040 & 3.8 & $27.9 \pm 0.86$ & $25.2 \pm 0.65$ & 338 \\
KVKY & 115 & $27.6 \pm 1.1$ & $24.3 \pm 0.66$ & 413 \\
KVOA & 160 & $26.7 \pm 1.3$ & $24.7 \pm 1.3$ & 250 \\
\hline
\end{tabular}

* Lifting condensation level or the height of cloud base $=125\left(T_{\text {air }}-T_{\text {dew }}\right)$ based on [12] (Eq. 16).

Now, according to [13]

$$
Z_{o}=1200 H_{s}\left(H_{s} / L_{p}\right)^{4.5}
$$


Here $H_{s}$ is the significant wave height and $L_{p}\left(=1.56 T_{p}^{2}\right)$ is the peak wave length and $T_{p}$ is the peak wave period. Note that the parameter $H_{s} / L_{p}$ is defined as the wave steepness and when $H_{s} / L_{p}>$ 0.020 , wind seas prevail [14].

In addition, following [1] (Equation (2.14), p. 68)

$$
g H_{s} / U *^{2}=0.061\left(g T_{p} / U *\right)^{3 / 2}
$$

Here $g\left(=9.8 \mathrm{~m} \mathrm{~s}^{-2}\right)$ is the gravitational acceleration. By substituting the value of $g$ into Equation (3), one gets

$$
U *=27.4 H_{s}^{2} / T_{p}^{3}
$$

During Sally both wind and wave parameters were measured at NDBC Buoys 42040 and 42012. These datasets can be employed to diagnose the variation of wind stress from deep to shallow water using aforementioned equations.

\section{Results}

According to [13], the shoaling depth equals approximately $0.25 L_{p}=0.25 * 1.56 T_{p}{ }^{2}=0.39 T_{p}{ }^{2}$. In addition, when $H_{s} / L_{p}>0.020$, wind seas prevail [14]. Using the peak or dominant wave period measurements from Buoy 42040 and 42012, one can estimate the relation between the friction velocity for atmospheric forcing and wave conditions for direct ocean response. This is done as follows:

\subsection{Deep Water Environment}

During the passage of Sally at 0150 UTC on 15 September 2020, Buoy 42040 stopped recording so the wind data from the anemometer located at $3.8 \mathrm{~m}$ was no longer available. However, enough datasets including $U_{3.8 \mathrm{~m}}, H_{\mathrm{s}}$, and $T_{\mathrm{p}}$ are useful for our analysis. Figure 8 shows our results that

$$
U *=28 H_{s}^{2} / T_{p}^{3}+0.12
$$

With a coefficient of determination $R^{2}=0.87$, meaning that $87 \%$ of the variation of the friction velocity can be explained by the wave effects. Also, since the difference between Equations (4) and (5) is small, our method is reasonable. 


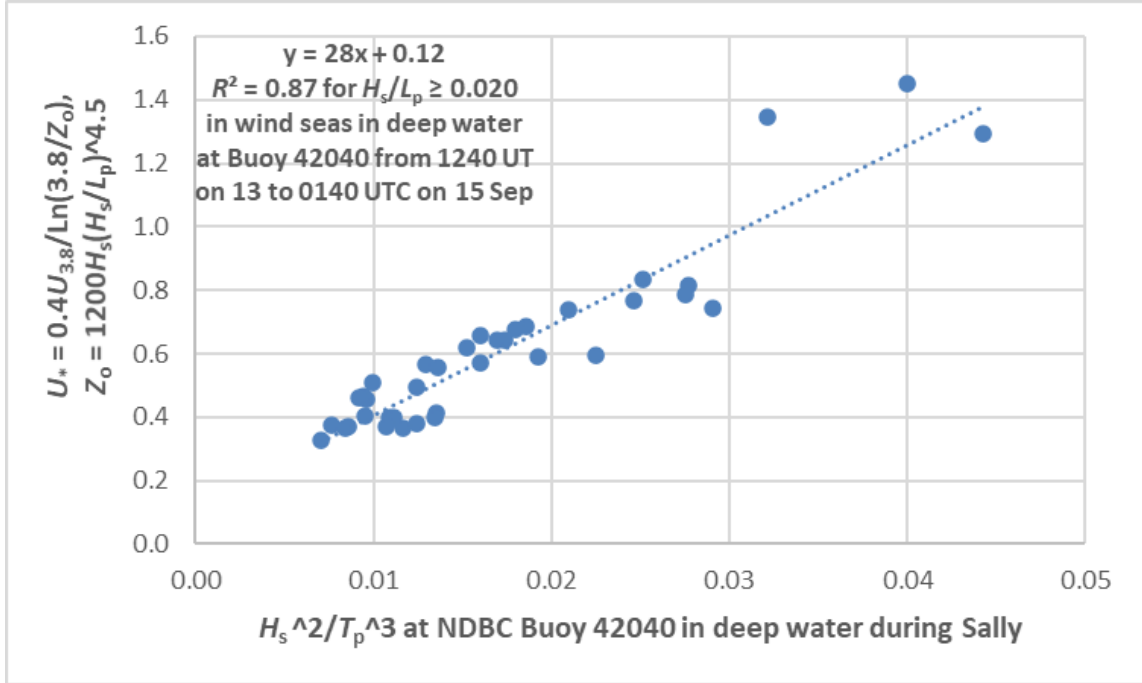

Figure 8 Relation between the friction velocity and wave parameters in the deep water at Buoy 42040 during Sally.

\subsection{Shoaling Wave Environment}

As stated previously, the shoaling depth $=0.39 T_{\mathrm{p}}{ }^{2}$ so that at the depth of $23.5 \mathrm{~m}$ at Buoy 42012 , when $T p>7.8$ seconds, shoaling waves prevail. Therefore, when all shoaling waves were taken into considerations, the relation between $U_{*}$ and wave parameters in the shallow water is found and presented in Figure 9. Our results for the shallow water environment is

$$
U *=30 H_{s}^{2} / T_{p}{ }^{3}+0.26
$$

with $R^{2}=0.90$, meaning that $90 \%$ of the variations in $U *$ can be explained by the wave response.

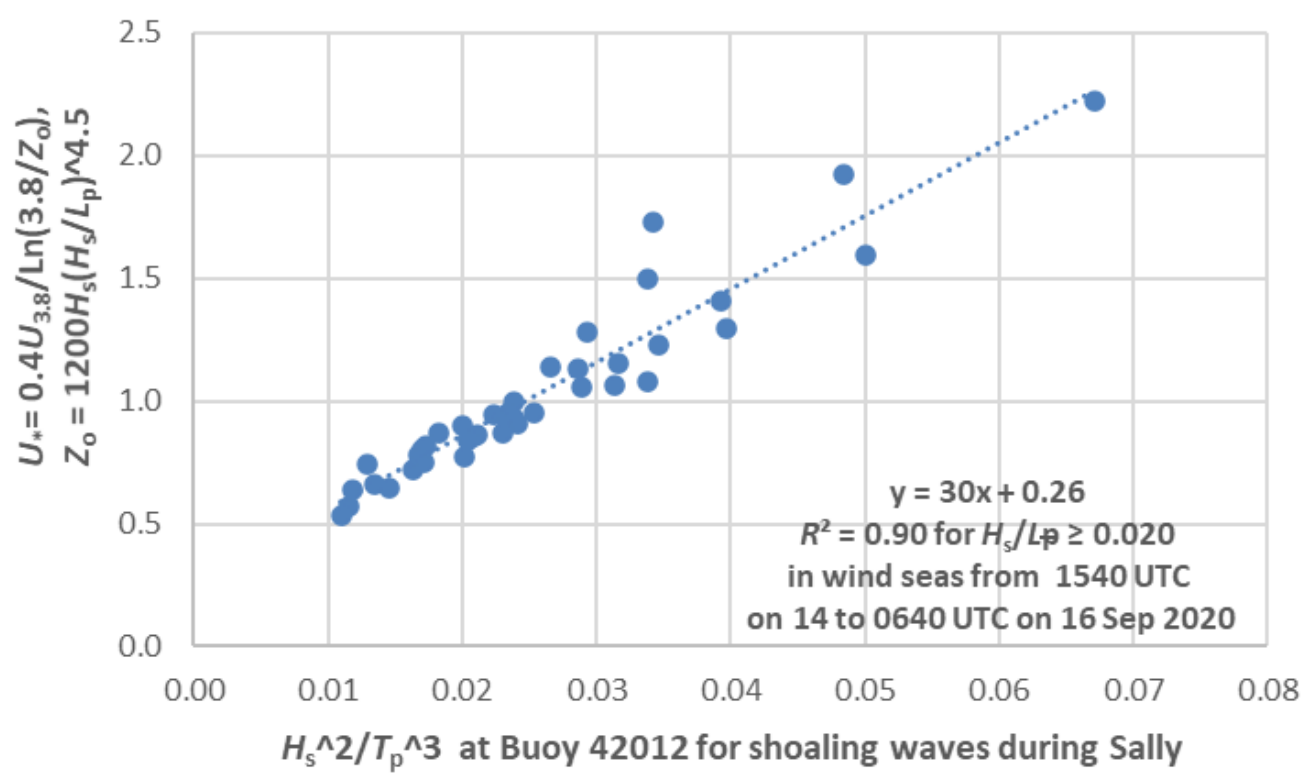

Figure 9 Relation between the friction velocity and wave parameters in the shallow water at Buoy 42012 during Sally. 


\subsection{Transitional Water-Depth Environment}

Because the shoaling depth may vary from $0.2 L_{p}$ to $0.25 L_{p}$ [13] and the bathymetry may also vary within a smaller area [15], $U *$ may change from deep to shoaling during a short period of time or within a smaller zone. In order to take these transitional water-depth environments into account, Figure 10 is presented. It is found that

$$
U *=31 H_{s}^{2} / T_{p}^{3}+0.14
$$

with $R^{2}=0.93$.

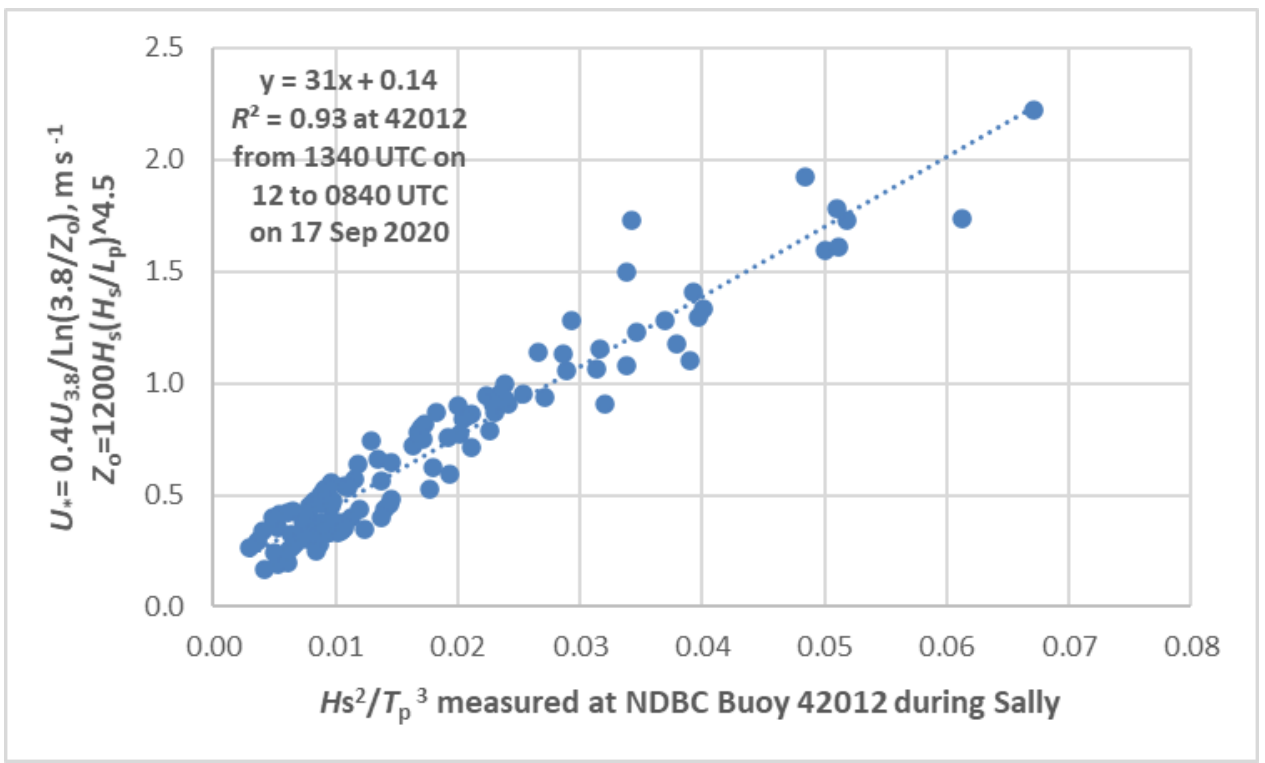

Figure 10 Relation between the friction velocity and wave parameters in a transitional water-depth environment at Buoy 42012 during Sally.

\section{Applications}

\subsection{Estimating the Storm Surge}

In 2005, Hurricane Katrina (Figure 11) devastated Louisiana/Mississippi coasts. At NDBC Buoy 42040, the largest $H_{\mathrm{s}}$ was measured at approximately $17 \mathrm{~m}$ and $T_{\mathrm{p}}$ was 14.3 seconds (Figure 12 ). The maximum storm surge on the Mississippi Gulf Coast reached $33 \mathrm{ft}(10 \mathrm{~m})$ as depicted in Figure 13. Because Buoy 42040 was located in deep water and by substituting these wave measurements into Equation (5), one gets $U_{*}=2.89 \mathrm{~m} \mathrm{~s}^{-1}$. Therefore, the wind stress which generated the storm surge [16] was $\tau=1.2 * 2.89^{2}=10 \mathrm{~Pa}$. Hence, the max storm surge of $10 \mathrm{~m}$ can be explained by the wind stress forcing. This is consistent with the wind-tress tide relation as proposed in [16]. 


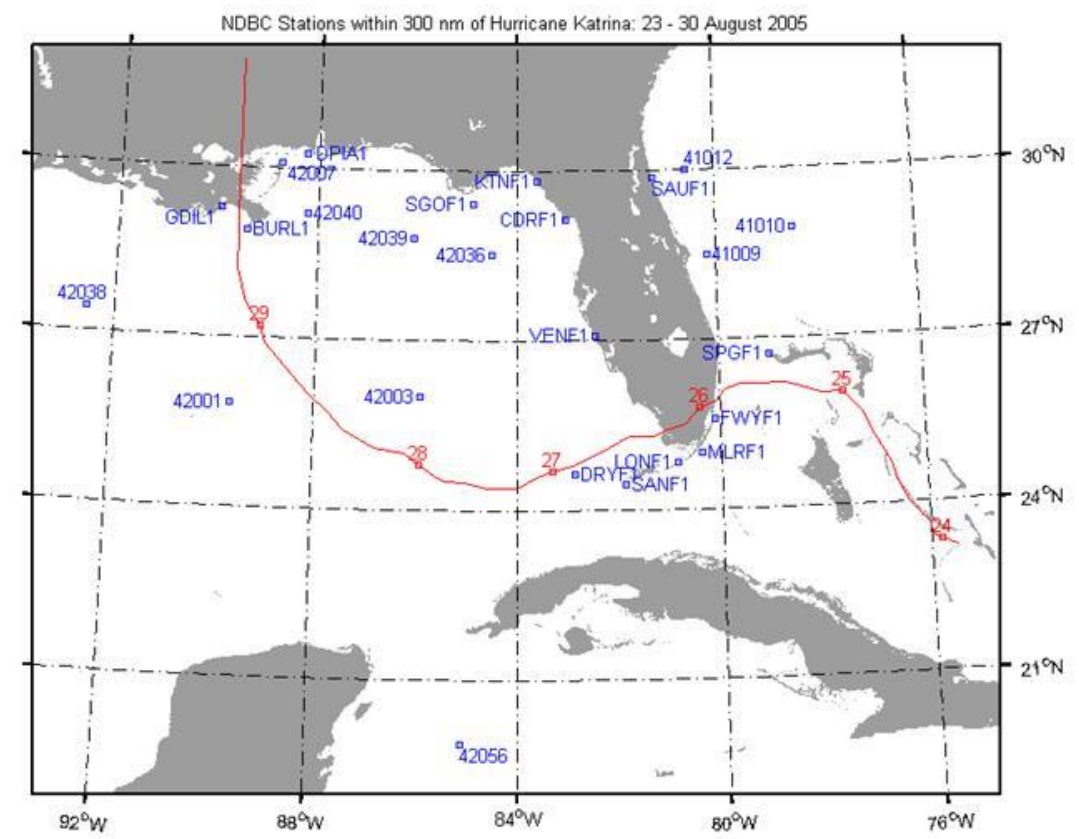

Figure 11 Hurricane Katrina's track and NDBC stations. Katrina's track (in red with the start of each day numbered) is from the positions of the National Hurricane Center's Forecasts/Advisories (http://www.ndbc.noaa.gov/hurricanes/2005/katrina/ ). NDBC Reports from the National Data Buoy Center's Stations in the Gulf of Mexico During the Passage of Hurricane Katrina (noaa.gov).

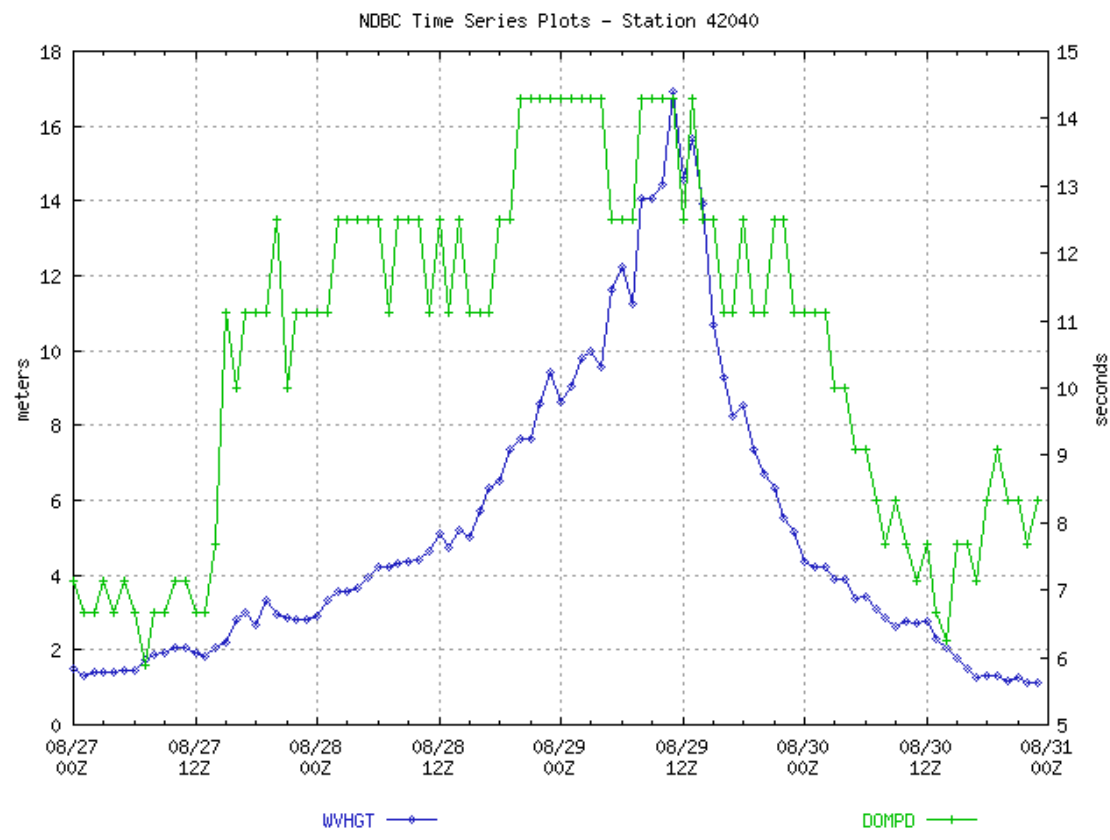

Figure 12 Measurements of $H_{\mathrm{s}}$ and $T_{\mathrm{p}}$ at NDBC Buoy 42040 during Hurricane Katrina in 2005 based on NDBC - Reports from the National Data Buoy Center's Stations in the Gulf of Mexico During the Passage of Hurricane Katrina (noaa.gov). 


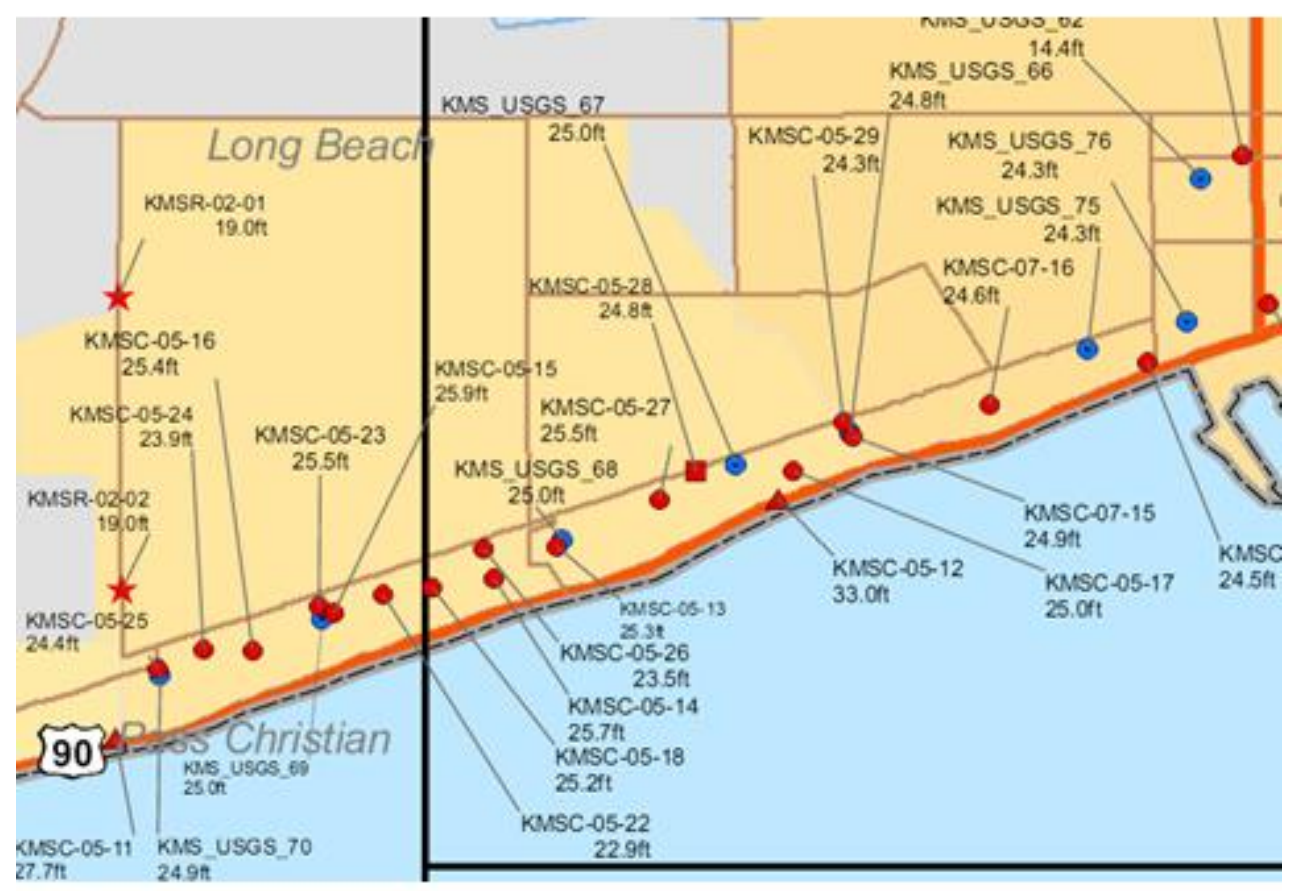

Figure 13 A section of high water mark surveys along the Mississippi Coast after Katrina [17].

\subsection{Estimating Near-Surface Currents}

In 2004 during Hurricane Ivan, extreme waves and currents were measured [15] as listed in Table 2 (except Mooring M6 because its $T_{\mathrm{p}}<$ mean wave period). Under these transitional water-depth conditions, Equation (7) is verified using Equation (8) which is based on [18] (Eq. 4), since $U *$ can also be estimated by the sea-surface current, $U_{\text {sesa }}$ as

$$
U_{\text {sea }}=0.57 U *
$$

Table 2 Measurements of waves and currents under Ivan's (2004) transitional waterdepth conditions [15]. Other parameters are computed based on equations as provided in the text.

\begin{tabular}{lllll}
\hline Parameters & M3 & M4 & M5 & Mean \\
\hline Water depth, m & 60 & 88 & 89 & 79 \\
$H_{\mathrm{s}}, \mathrm{m}$ & 18.0 & 16.1 & 17.7 & 17.3 \\
$T_{\mathrm{p}}, \mathrm{s}$ & 14.8 & 13.6 & 14.8 & 14.4 \\
$U_{\text {sea }}, \mathrm{m} \mathrm{s}^{-1}$ & 1.73 & 1.96 & 1.91 & 1.87 \\
$U_{*}=U_{\text {sea }} /$ O.57,Eq. (8) & 3.04 & 3.44 & 3.35 & 3.28 \\
$U_{*}, \mathrm{~m} \mathrm{~s}^{-1}$, Eq. (7) & 3.24 & 3.33 & 3.15 & 3.24 \\
$U_{10}, \mathrm{~m} \mathrm{~s}^{-1}$, Eq. (9) & 45 & 45 & 45 & 45 \\
$U_{*} / H_{\mathrm{s}}$ & 0.18 & 0.21 & 0.18 & 0.19 \\
$U_{\text {sea }} / H_{\mathrm{s}}$ & 0.10 & 0.12 & 0.11 & 0.11 \\
\hline
\end{tabular}




\subsection{Estimating Wind Speed with Height}

For air-sea interaction studies, the wind speed at $10 \mathrm{~m}, U_{10}$, is needed. From Equation (1), by setting $Z=10 \mathrm{~m}$. we have

$$
U_{10}=2.5 U * \ln \left(10 / Z_{o}\right)
$$

Using Equations (2) and (5) for deep water environment, Equation (9) is validated in Figure 14 during Hurricane Wilma in 2005 near NDBC Buoy 42056 in the northwestern Caribbean Sea.

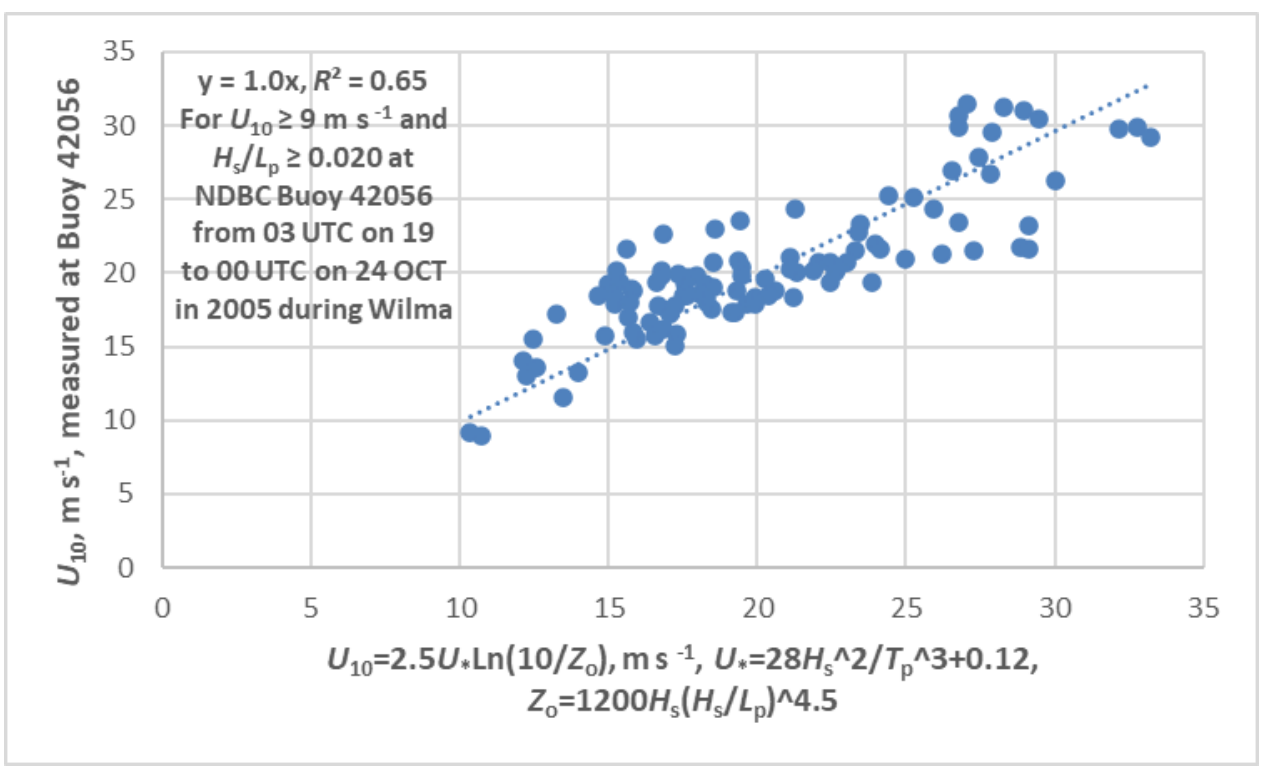

Figure 14 Validation of Equation (9) during Hurricane Wilma in 2005.

Another example for the estimation of $U_{10}\left(=45 \mathrm{~m} \mathrm{~s}^{-1}\right)$ over the transitional water is presented in Table 2. Our results are consistent with [19] (Figure 3 for the highest $U_{10}=45 \mathrm{~m} \mathrm{~s}^{-1}$ ). Using Equations (6) and (9), an example to estimate $U_{10}$ for a shallow water environment is presented in the next subsection.

\subsection{Value-Added Applications for CDIP Buoys}

The Coastal Data Information Program (CDIP) (CDIP About (ucsd.edu)) is an extensive network for monitoring waves and beaches along the coastlines of the United States. Since its inception in 1975 , the program has produced a vast database of publicly-accessible environmental data for use by coastal engineers and planners, scientists, mariners, and marine enthusiasts. CDIP is operated by the Ocean Engineering Research Group (OERG), part of the Integrative Oceanography Division (IOD) at Scripps Institution of Oceanography (SIO).

On 29 August 2021 Hurricane Ida devastated Southeast Louisiana (NWS LIX - Hurricane Ida Event page (weather.gov)). Figure 15 shows portions of Ida's track and met-ocean stations employed in this study. Table 3 is a list of largest $H_{s}$ measurement from Buoy 42084 (also named CDIP Station 256) on 29 August 2021 during Ida. Since the CDIP buoys do not have the wind measurements, we can estimate $U_{*}$ and $U_{10}$ as value-added parameters based on aforementioned equations. This is accomplished as follows: 


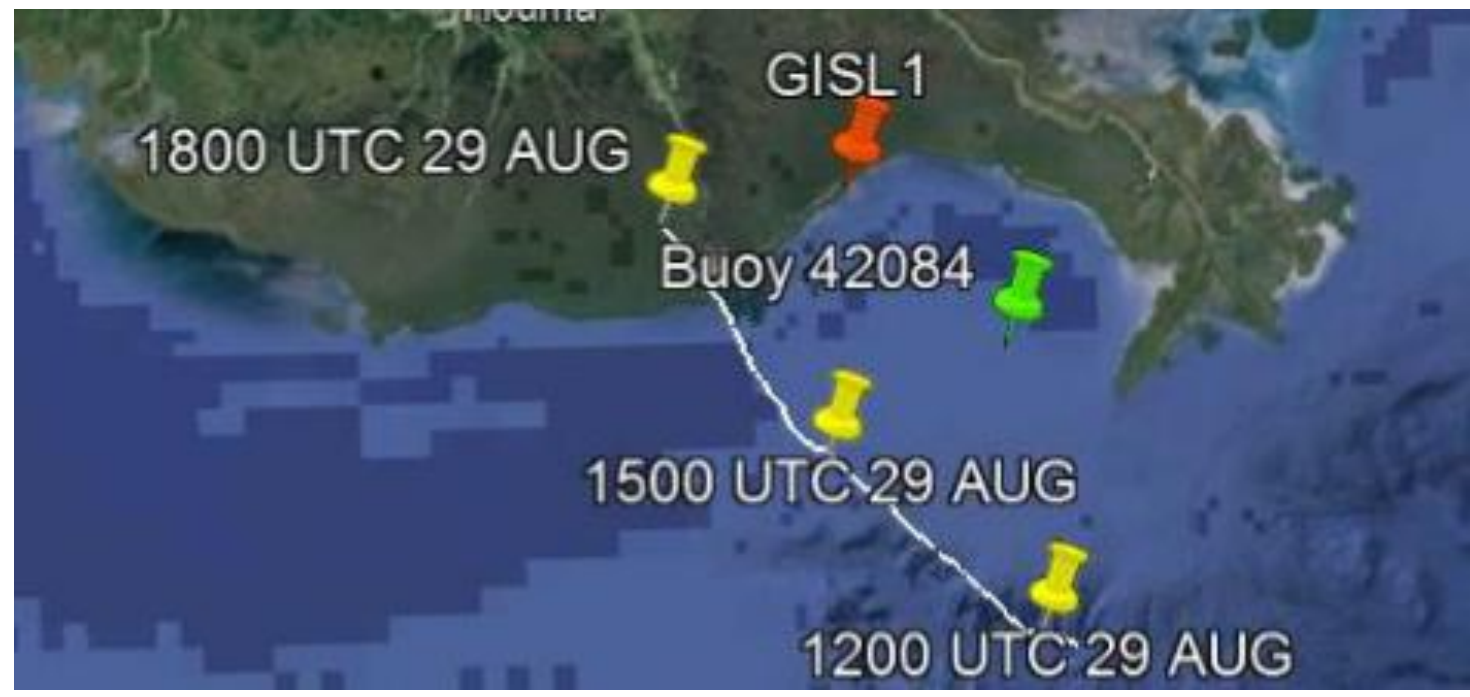

Figure 15 Portions of Ida's track from 1200 UTC to 1800 UTC on 29 August 2021and metocean stations used in this study.

Table 3 Largest $H_{\mathrm{s}}$ measurement at NDBC Station 42084 (CDIP Buoy 256) at 1700 UTC on 29 August 2021 at water depth $=44.8$ meters in shoaling wave conditions during Hurricane Ida (Data source: https://www.ndbc.noaa.gov/data/stdmet/Aug/42084.txt). The highest sustained wind speed at $9.3 \mathrm{~m}$ above the mean sea level at the National Ocean Service (NOS) Station at GISL1 was $32.4 \mathrm{~m} \mathrm{~s}^{-1}$ occurred at 1730 UTC on 29 August 2021 during Ida (Data source:

https://www.ndbc.noaa.gov/view text file.php?filename=gisl182021.txt.gz\&dir=data/ stdmet/Aug/ ).

\begin{tabular}{ccccccc}
\hline$H_{\mathrm{s}}$ & $T_{\mathrm{p}}$ & Wave dir. & $H_{\mathrm{s}} / L_{\mathrm{p}}$ & $U_{*}$ & $U_{10}, 42084$ & $U_{9.3, \mathrm{GISL1}}$ \\
\hline $\mathrm{m}$ & $\mathrm{s}$ & degrees & & $\mathrm{m} \mathrm{s}^{-1}$ & $\mathrm{~m} \mathrm{~s}^{-1}$ & $\mathrm{~m} \mathrm{~s}^{-1}$ \\
8.34 & 11.11 & 200 & 0.043 & 1.78 & 32 & 32 \\
\hline
\end{tabular}

Since $T_{\mathrm{p}}=11.11$ second, the shoaling depth was $0.39 * 11.11^{2}=48 \mathrm{~m}$. Because the water depth at Buoy 42084 was $44.8 \mathrm{~m}$, shoaling wave conditions occurred (Table 3). Using Equations (6) and (9), both $U_{*}$ and $U_{10}$ can be estimated. It is found that the estimated value of $U_{10}$ is nearly the same as that measured at $9.3 \mathrm{~m}$ at the National Ocean Service (NOS) station at GISL1 as showing in Table 3. Furthermore, the values of $U_{\text {sea }}$ around $1 \mathrm{~m} \mathrm{~s}^{-1}$ as depicted in Figure 16 can be explained by the wind stress forcing using Equation (8). According to the National Weather Service (NWS) (NWS LIX - Hurricane Ida Event page (weather.gov)), the Grand Isle, LA area near Station GISL1 experienced over $3 \mathrm{~m}$ (10ft) storm surges. These coastal floods can also be explained physically by the wind stress

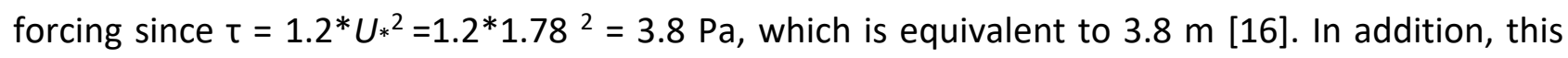
magnitude of the wind stress plus the associated storm surges was more than enough to damage the floating marshes and other wetland plants [3]. 


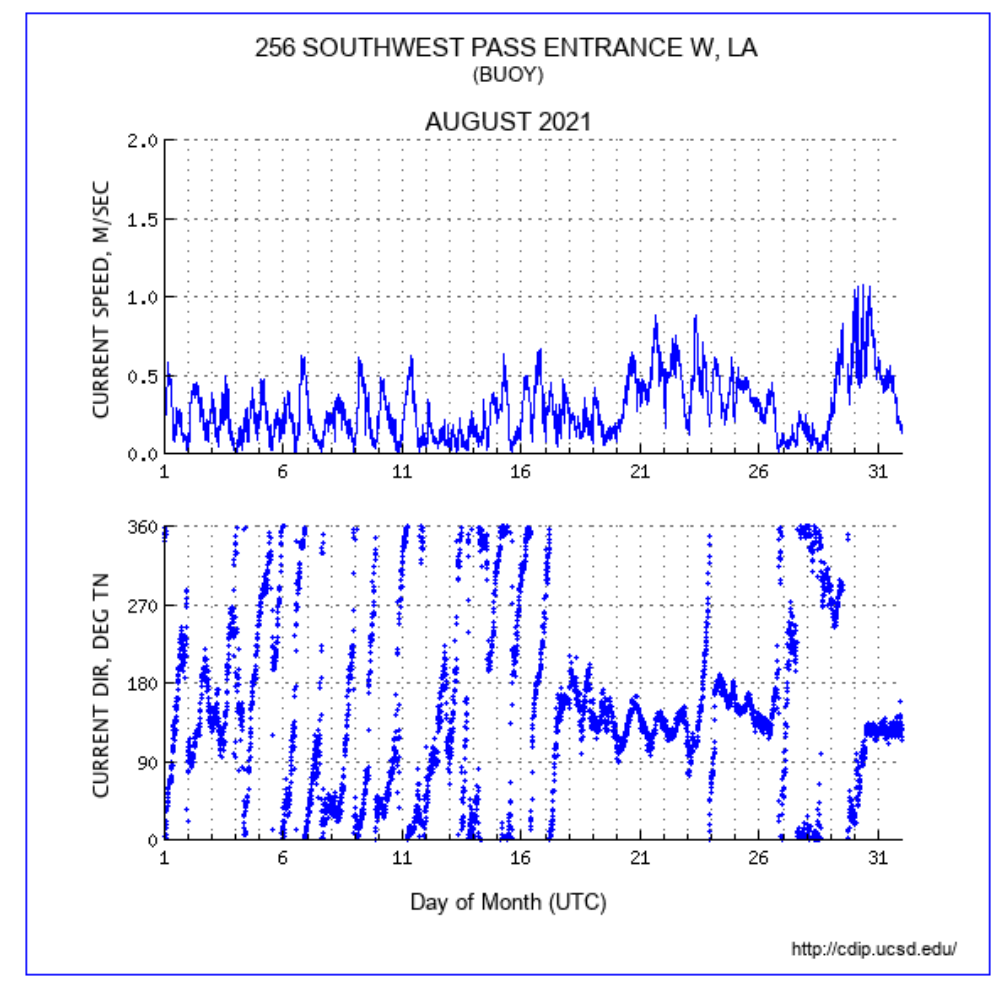

Figure 16 Large near-surface currents (around $1 \mathrm{~m} \mathrm{~s}^{-1}$ ) generated by Ida at Buoy 42084 on 29-30 August 2021 based on Station Data Page Home (ucsd.edu).

\subsection{Estimating Seabed Scour}

According to [19], strong surface waves and currents generated by major hurricanes can produce extreme forces at the seabed that scour the sea floor and cause massive underwater mudslides. The combined current-wave stress, $\tau_{\mathrm{cw}}$, on the sea floor is approximately related to the wind stress, $U_{10}{ }^{2}$, that, for $U_{10}>15 \mathrm{~m} \mathrm{~s}^{-1}$,

$$
\tau_{c w}=0.0004 U_{10}^{2}
$$

Note that the unit of seabed stress is $\mathrm{N} \mathrm{m}^{-2}$ or $\mathrm{Pa}$.

In order to estimate the seabed scour, Figure 17 is presented [20] (for the datasets) so that

$$
d_{50}=-1.17 \tau_{c w}^{2}+3.37 \tau_{c w}-0.33
$$

with $R^{2}=1.0$. Here $\mathrm{d}_{50}$ is the mean grain size in $\mathrm{mm}$ and $\tau_{\mathrm{cw}}$ is the critical shear stress on the seabed to initiate the resuspension of the marine sediments. 


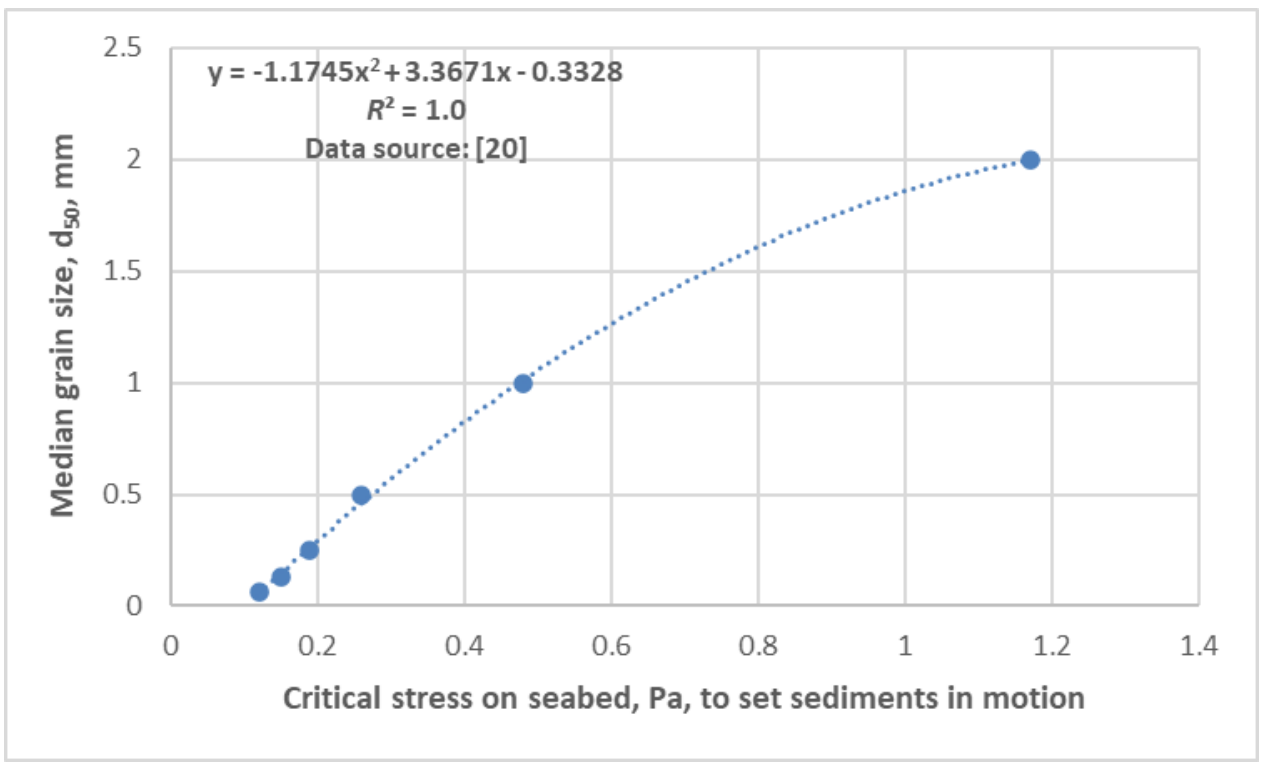

Figure 17 Relation between mean grain size, $\mathrm{d}_{50}$ in $\mathrm{mm}$, and the critical seabed stress to initiate resuspension of marine sediments.

It can be seen that during Ivan (see Table 2), $U_{10}=45 \mathrm{~m} \mathrm{~s}^{-1}$. By substituting this wind speed into Equation (10), $\tau_{c w}=0.81 \mathrm{~Pa}$. Now, substituting this $\tau_{\mathrm{cw}}$ value into Equation (11), $\mathrm{d}_{50}=1.63 \mathrm{~mm}$, meaning those sediments with $d_{50}$ finer than $1.6 \mathrm{~mm}$ would have been removed from the sea bed in the mooring areas as listed in Table 2. This physical mechanism may be used to explain the significant bottom scour on the outer shelf at water depths as deep as $90 \mathrm{~m}$ during the passage of Hurricane Ivan [15]. Using similar procedure for Hurricane Ida in 2021 (Table 3), we have $\tau_{\mathrm{cw}}=0.41$ $\mathrm{Pa}$ and $\mathrm{d}_{50}=0.85 \mathrm{~mm}$, indicating that seabed area from $48 \mathrm{~m}$ water depth shoreward into the wetlands with sediments finer than $0.85 \mathrm{~mm}$ would have been scoured and removed by Ida.

\section{Discussion}

In deep water, according to [7], for the period of growing wind seas during Hurricane Matthew in 2017,

$$
U_{10}=35 H_{s} / T_{p}
$$

This equation is further verified in Figure 18 during Katrina (see Figures 11 and 12). 


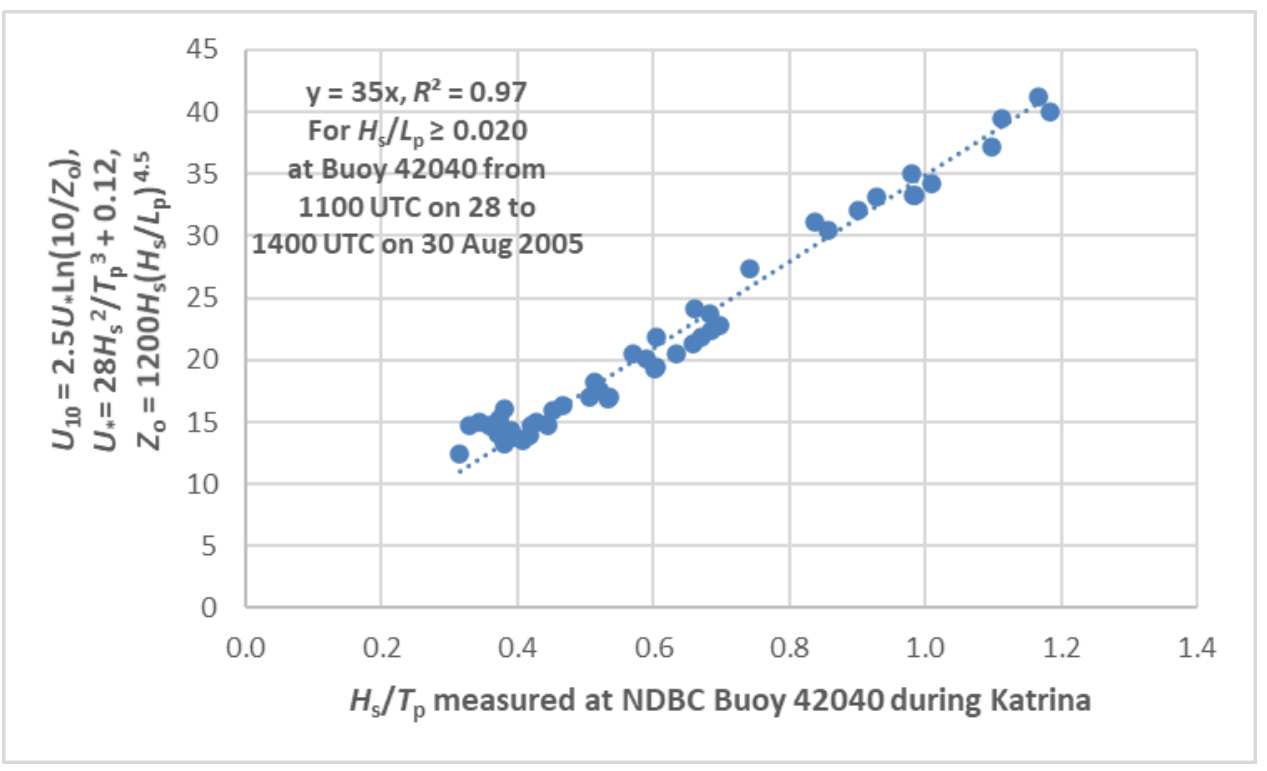

Figure 18 Verification of Equation (12) during Katrina.

Now, dividing Equations (4) by (12) and setting $L_{p}=1.56 T_{\mathrm{p}}{ }^{2}$, we have, for $U_{10}>9 \mathrm{~m} \mathrm{~s}^{-1}$ during wind seas and from Introduction,

$$
U * / U_{10}=C_{d}^{0.5}=\alpha H_{s} / L_{p}+\beta
$$

Here " $\alpha$ " and " $\beta$ " are the coefficients to be determined from the field measurements.

Equation (13) is verified in Figure 19 for the deep water at Buoy 42040 during Sally that,

$$
U * / U_{10}=C_{d}^{0.5}=0.83 H_{s} / L_{p}+0.017
$$

and in Figure 20 for the shoaling water at Buoy 42012 during Sally that,

$$
U * / U_{10}=C_{d}^{0.5}=0.81 H_{s} / L_{p}+0.018
$$

In order to extend Equation (14) into larger wave height such as at Buoy 42040 during Katrina $H_{s}$ $=17 \mathrm{~m}$, (see Figures 11 and 12), Figure 21 is presented that,

$$
U * / U_{10}=C_{d}^{0.5}=1.05 H_{s} / L_{p}+0.0125
$$

Above equations indicate that $C_{d}$ is very sensitive to $H_{s} / L_{p}$, Examples of the variations in the wave steepness on the right and left track during Katrina (see Figure 11) are provided in Figures 22 and 23, respectively. It is clear that on the right, wind seas prevailed and on left, mixed seas were the general rule. Therefore, caution must be exercised to use a proper $C_{d}$ for different wave conditions. Equation (13) may be employed to explain why so many different $C_{d}$ formulations existed in the literature. Future works should include the comparison between these proposed $C_{d}$ formulae against implemented formula in waves model such as Zijlema 2012 formula [21] and in storm surge dynamics $[22,23]$. 
Adv Environ Eng Res 2022; 3(1), doi:10.21926/aeer.2201006

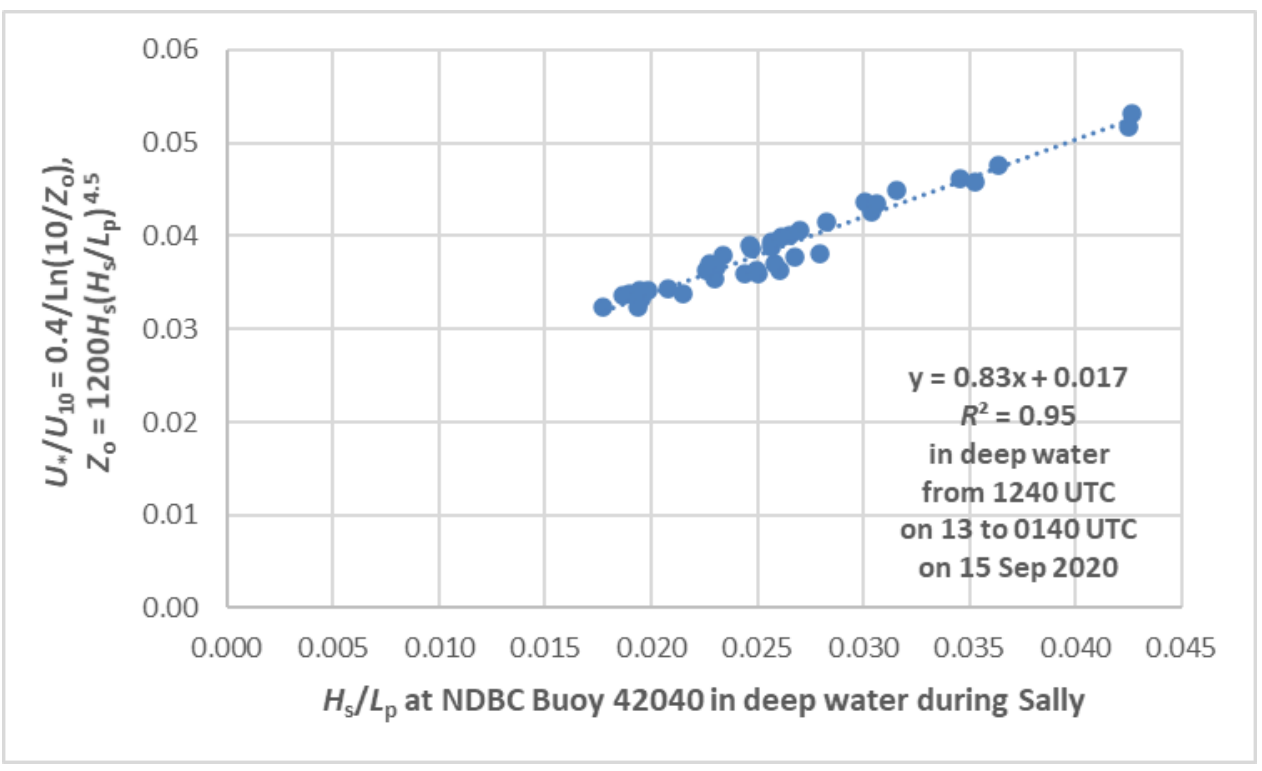

Figure 19 Relation between dimensionless ratio of $C_{d}{ }^{0.5}$ and wave steepness in deep water during Sally.

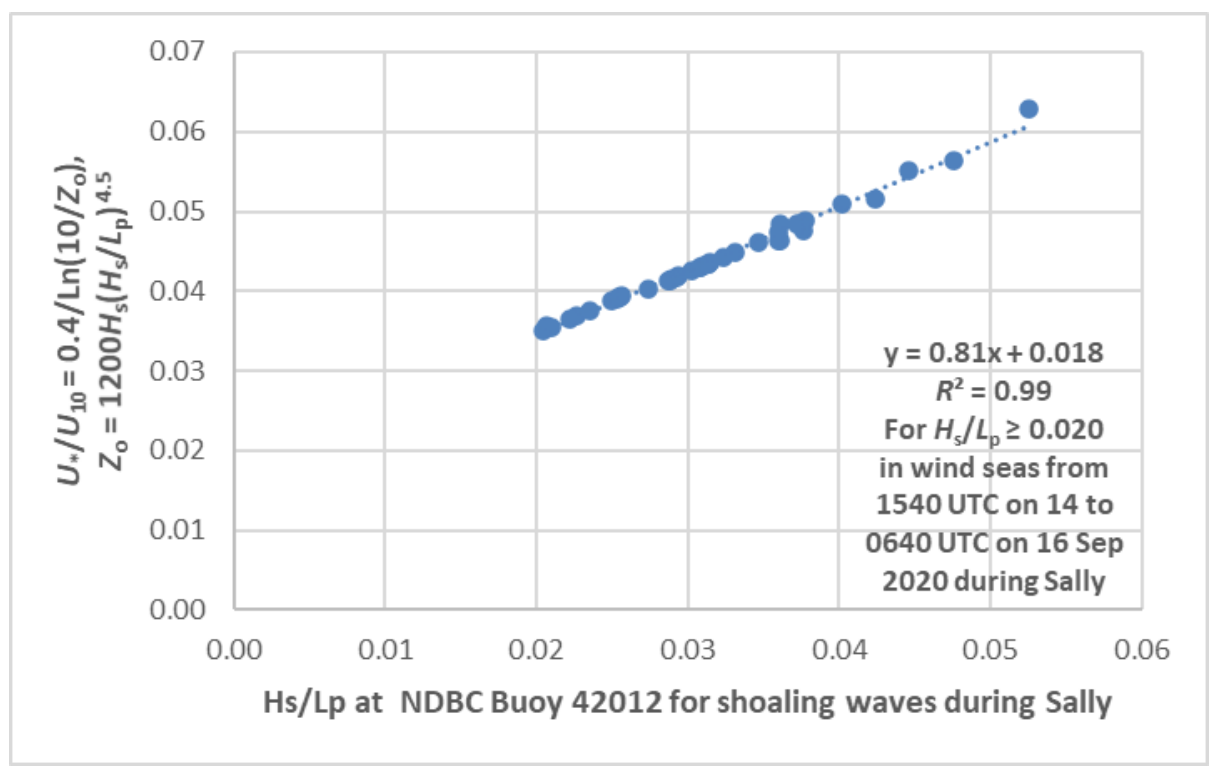

Figure 20 Relation between dimensionless ratio of $C_{d}{ }^{0.5}$ and wave steepness in shoaling water during Sally. 


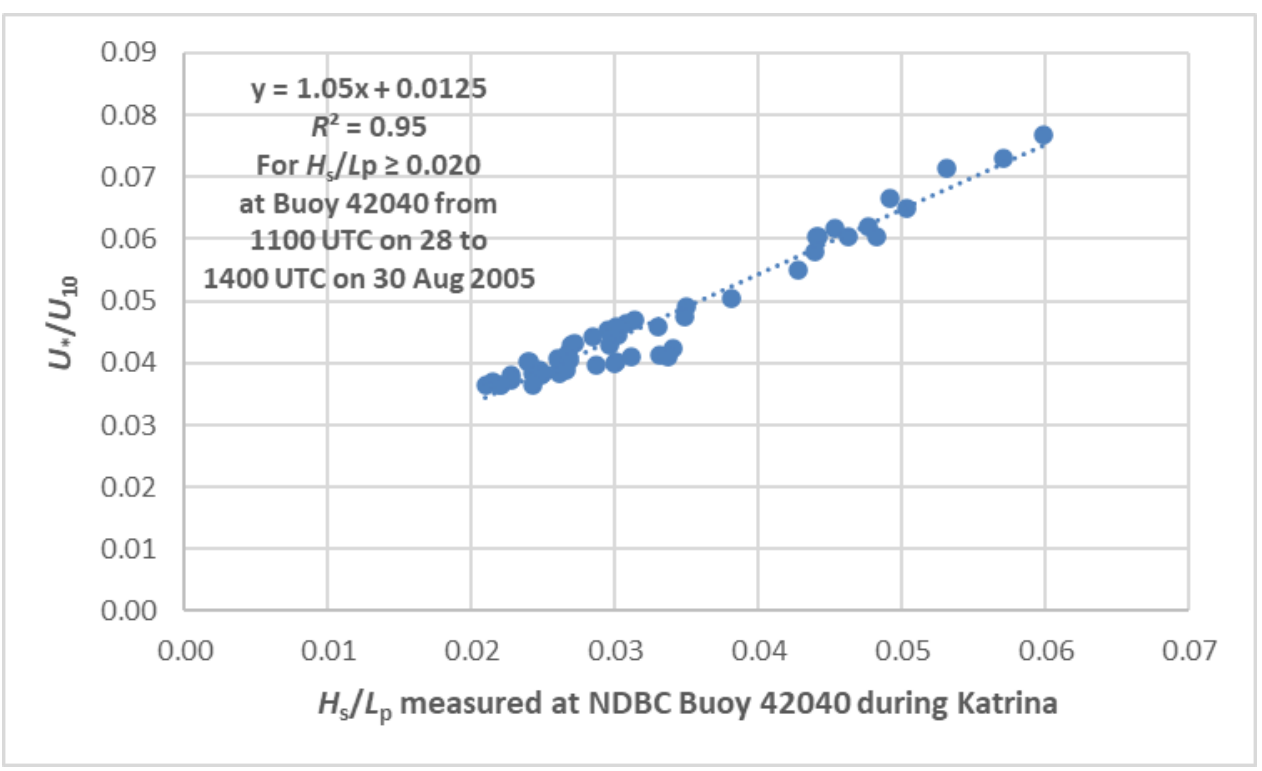

Figure 21 Relation between dimensionless ratio of $C_{d}{ }^{0.5}$ and wave steepness in deep water at Buoy 42040 during Katrina.

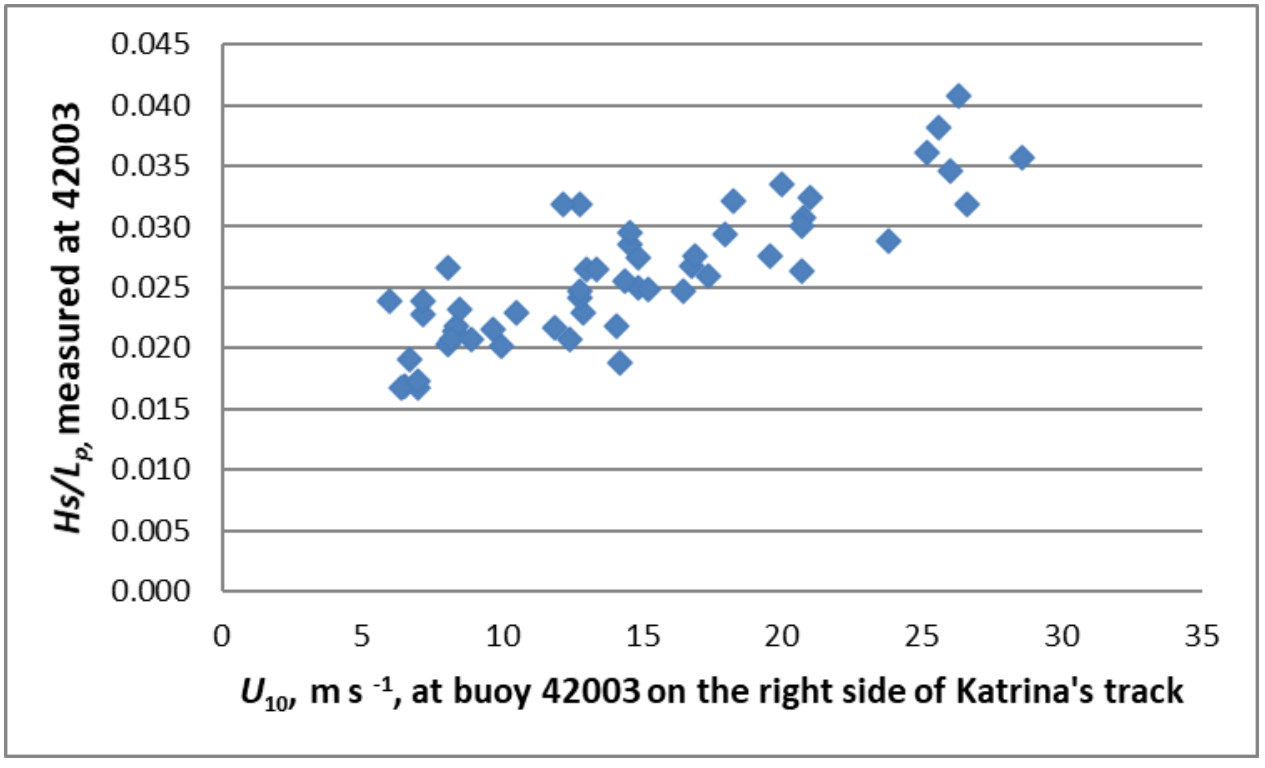

Figure 22 Variation of wave steepness on the wind speed on the right side of Katrina's track (see Figure 10). 


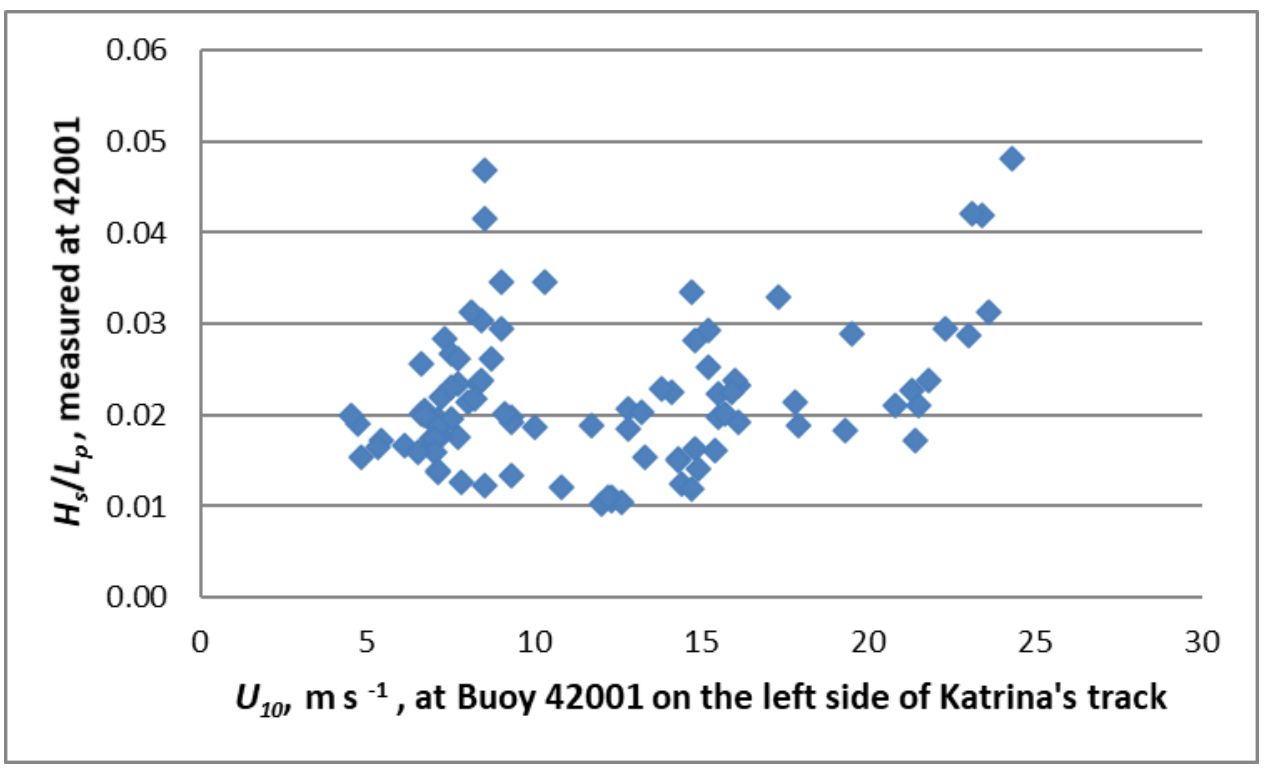

Figure 23 Variation of wave steepness on the wind speed on the left side of Katrina's track see Figure 10).

Finally, from the literature, in order to estimate $Z_{o}$ or $C_{d}$, the inverse wave age, $U_{10} / C_{p}$, is used $[24,25]$. By dividing both sides of Equation (12) by the wave celerity, $C_{p}=1.56 T_{p}$, one gets

$$
U_{10} / C_{p}=35 H_{s} / L_{p}
$$

Equation (17) shows that $U_{10} / C_{p}$ is related linearly to the wave steepness, which is verified in Figure 24. Note that because the wave age requires both values of wind speed at $10 \mathrm{~m}$ and wave period whereas wave steepness only wave height and period which are available routinely in all buoy measurements including those from CDIP, the usage of wave steepness is preferred operationally. As stated in [14], using several datasets, the steepness model did better than the wave-age model when $H_{s} / L_{p} \geq 0.020$ as employed in Equation (2) in this study.

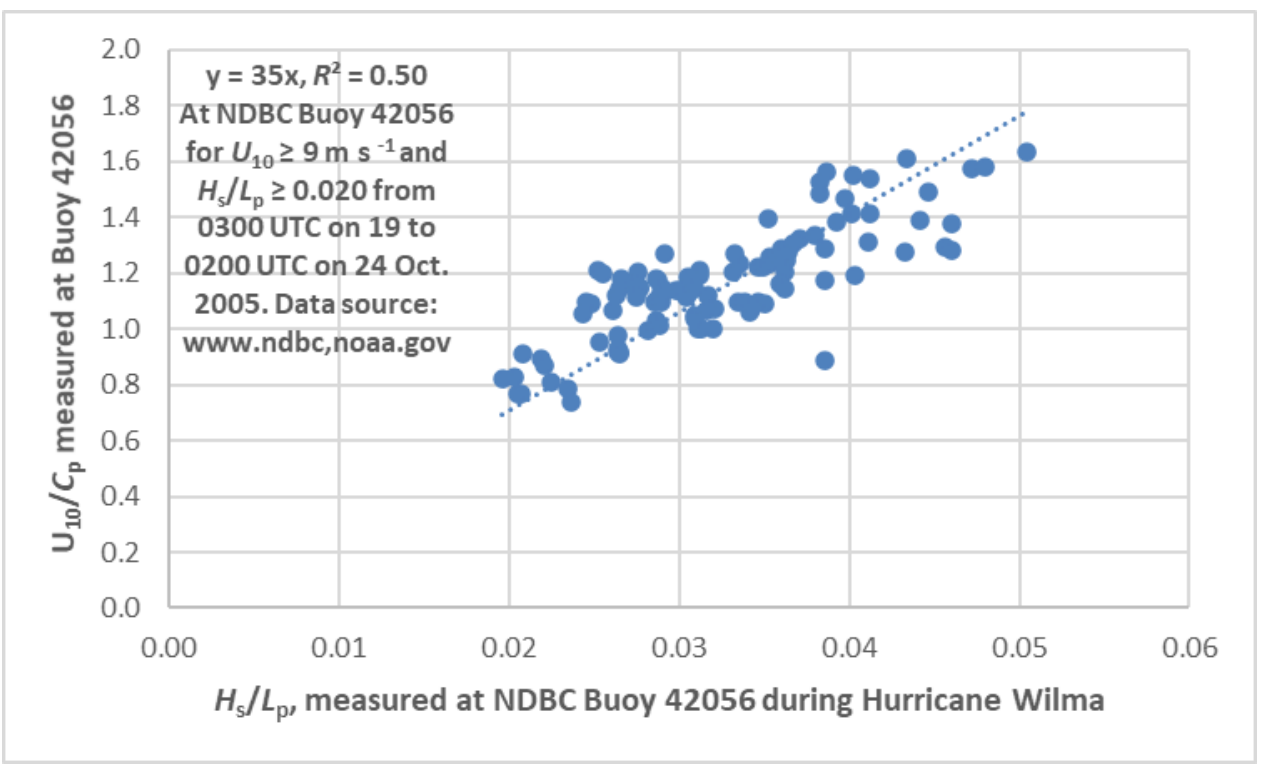

Figure 24 Verification of Equation (17) during Hurricane Wilma. 


\section{Conclusions}

In the literature nearly all estimates of the wind stress on the water surfaces were based on the wind speed including the wave-age formulation which also requires the wind speed information. This study is motivated by the need to estimate the wind stress by the extensive datasets such as CDIP buoys which have only the wave measurements. During Hurricane Sally in 2020, two NDBC buoys (one was located in deep water and the other in shoaling water) provided both wind and wave measurements. Analyses of these measurements show that the friction velocity can be used to estimate the wind stress from deep to shallow water environments using the wave parameters only as presented in Equations (5) through (7). Applications of the proposed formulas for the estimations of storm surge, surface currents, wind speed and seabed scours are also presented. Finally, it is demonstrated that large variations of the drag coefficient and wave-age formulations in the literature can be explained using the parameter of wave steepness.

\section{Acknowledgments}

Appreciation goes to CDIP, FEMA, NDBC, NHC, NOS, NWS, and RAMMB for providing datasets used in this research.

\section{Author Contributions}

The author, Prof. S. A. Hsu, did all the work.

\section{Competing Interests}

The authors have declared that no competing interests exist.

\section{References}

1. Csanady GT. Air-sea interaction: laws and mechanisms. Cambridge, England: Cambridge University Press; 2001.

2. Edson JB, Jampana V, Weller RA, Bigorre SP, Plueddemann AJ, Fairall CW, et al. On the exchange of momentum over the open ocean. J Phys Oceanogr. 2013; 43: 1589-1610.

3. Dingler JR, Hsu SA, Foote AL. Wind shear stress measurements in a coastal marsh during Hurricane Andrew. J Coast Res. 1995: 295-305.

4. Morton RA, Barras JA. Hurricane Impacts on coastal wetlands: A half-century record of stormgenerated features from Southern Louisiana. J Coast Res. 2011; 27: 27-43.

5. Bryant KM, Akbar M. An exploration of wind stress calculation techniques in hurricane storm surge modeling. J Mar Sci Eng. 2016; 4: 58.

6. Jimenez PA, Dudhia J. On the wind stress formulation over shallow waters in atmospheric models. Geosci Model Dev Discuss. 2014; 7: 9063-9077.

7. Hsu SA, He Y, Shen H. Buoy measurements of wind-wave relations during Hurricane Matthew in 2016. J Phys Oceanogr. 2017; 47: 2603-2609.

8. Hsu SA. Estimating met-ocean parameters during a tropical cyclone for marine science and engineering. J Energy Power Technol. 2021; 3: 16.

9. Hsu SA. Coastal meteorology. Cambridge, Massachusetts: Academic Press; 1988. 
10. Hsu SA. Estimating overwater friction velocity and exponent of power-law wind profile from gust factor during storms. J Waterw Port Coast Ocean Eng. 2003; 129: 174-177.

11. Woodward JL. Atmospheric stability classification schemes. In: Estimating the flammable mass of a vapor cloud. New York: American Institute of Chemical Engineers; 1998.

12. Hsu SA. A relationship between the Bowen Ratio and sea-air temperature difference under unstable conditions at sea. J Phys Oceanogr. 1998; 28: 2222-2226.

13. Taylor PK, Yelland MJ. The dependence of sea surface roughness on the height and steepness of the waves. J Phys Oceanogr. 2001; 31: 572-590.

14. Drennan WM, Taylor PK, Yelland MJ. Parameterizing the sea surface roughness. J Phys Oceanogr. 2005; 35: 835-848.

15. Teague WJ, Jarosz E, Wang DW, Mitchell DA. Observed oceanic response over the upper continental slope and outer shelf during Hurricane Ivan. J Phys Oceanogr. 2007; 37: 2181-2206.

16. Hsu SA. Storm surge in New York during Hurricane Sandy in 2012: A verification of the windstress tide relation. Boundary Layer Meteorol. 2013; 148: 593-598.

17. FEMA. Final coastal and riverine high water mark collection for Hurricane Katrina in MS. Washington, D.C.: FEMA; 2006; FEMA-1604-DR-MS.

18. Wu J. Sea-surface drift currents induced by wind and waves. J Phys Oceanogr. 1983; 13: 14411451.

19. Wijesekera H, Wang DW, Teague WJ, Jarosz E. High sea-floor stress induced by extreme hurricane waves. Geophys Res Lett. 2010; 37. doi:10.1029/2010GL043124.

20. Soulsby RL. Dynamics of marine sands - a manual for practical applications. London: Thomas Telford Publications; 1997.

21. Zijlema M, van Vledder G.Ph., Holthuijsen LH. Bottom friction and wind drag for wave Models. Coast Eng. 2012; 65: 19-26.

22. Niu Q, Xia M. The role of wave-current interaction in Lake Erie's seasonal and episodic dynamics. J Geophys Res Oceans. 2017; 122: 7291-7311.

23. Mao M, Xia M. Wave-current dynamics and interactions near the two inlets of a shallow lagooninlet-coastal ocean system under hurricane conditions. Ocean Model. 2018; 129: 124-144.

24. Takagaki N, Kamori S, Suzuki N, Iwano K, Kurose R. Mechanism of drag coefficient saturation at strong speeds. Geophys Res Lett. 2016; 43: 9829-9835.

25. Donelan MA, Dobson FW, Smith SD, Anderson RJ. On the dependence of sea surface roughness on wave development. J Phys Oceanogr. 1993; 23: 2143-2149. 
Adv Environ Eng Res 2022; 3(1), doi:10.21926/aeer.2201006

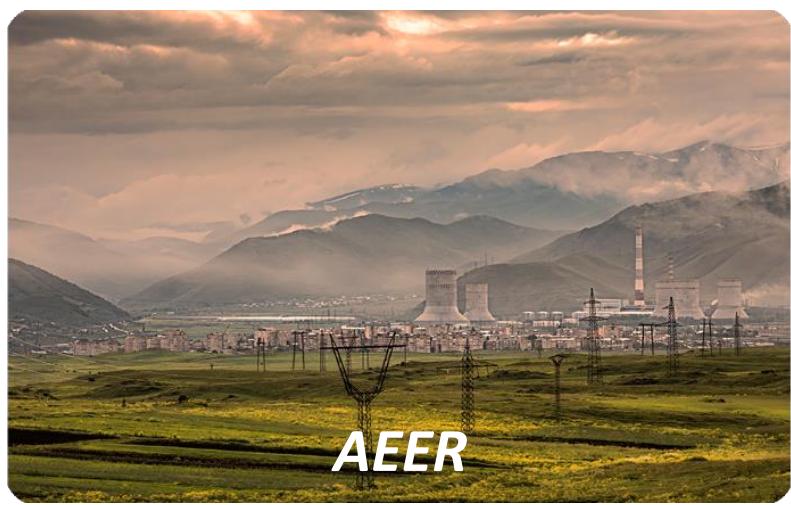

Enjoy $A E E R$ by:

1. Submitting a manuscript

2. Joining in volunteer reviewer bank

3. Joining Editorial Board

4. Guest editing a special issue

For more details, please visit:

http://www.lidsen.com/journals/aeer 